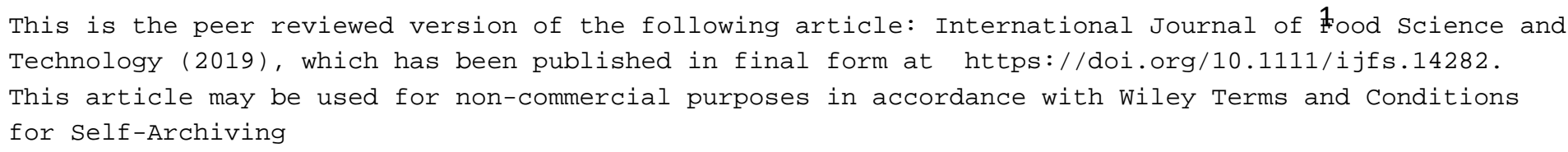

\title{
Aerobic industrial processing of Empeltre cv. natural black olives and product characterization
}

\author{
Eduardo Medina, Pedro García-García, Concepción Romero, Antonio de Castro \& \\ Manuel Brenes* \\ Instituto de la Grasa (IG-CSIC), University Campus Building 46, Ctra. Utrera km 1, \\ 41013-Seville, Spain \\ Correspondent: E-mail: brenes@cica.es
}




\begin{abstract}
Summary
The fermentation of natural black olives is currently carried out under anaerobic conditions. This work investigates the aerobic fermentation of this product in tanks containing $16000 \mathrm{~kg}$ of Empeltre olives during two seasons. The microorganisms in brines were yeasts in all cases, whereas lactic acid bacteria growth was only observed in some tanks. Consequently, the $\mathrm{pH}$ during fermentation was in most cases higher than recommended 4.3 units. However, the Empeltre olive brines displayed bactericidal effect against Salmonella enterica, Sthapylococcus aureus, Escherichia coli and Listeria monocytogenes, with a $5 \log$ population drop in one or 24 hours depending on the brine age so that these olive brines are a harsh environment for the growth of these pathogens. It was found HyEDA as the major phenolic compound in both brine and olive pulp at the beginning of fermentation that slowly hydrolyzed into hydroxytyrosol that reached a concentration up to $1500 \mathrm{mg} / \mathrm{kg}$.
\end{abstract}

Keywords: Fermentation, Pathogenic, phenols, Triterpenic acids 


\section{Introduction}

The main trade preparations of table olives are the Spanish-style green, the black ripe, and the natural black olives. Among them, the natural black olives have been elaborated in most Mediterranean countries for centuries. The method consists in harvesting the fruit when fully ripened, washing and brining for months before packing (Tassou et al., 2002). In many countries, the industrial processing of this type of olives is carried out into barrels or small tanks (150-2000 kg) to avoid the accumulation of $\mathrm{CO}_{2}$ inside the fruits due to the anaerobic conditions and therefore the formation of gas pocket in the olives (Juarez-Romero et al., 2015). The aerobic fermentation of natural black olives of the Hojiblanca cultivar was studied at laboratory scale many years ago (García et al., 1985), and this technology is currently employed for the preservation of green olives (De Castro et al., 2007) but it has never been studied and reported the industrial implementation of the aerobic fermentation of natural black olives.

Many variables may influence the onset of the fermentation of the natural black olives and the quality and safety of the final product including the level of salt, initial acidification, temperature and type of fermentation, among others. The level of salt is one of the main variables, $6 \% \mathrm{NaCl}$ were found the best concentration for the growth of lactic acid bacteria (LAB) in brines of natural black olives of the Conservolea cultivar (Tassou et al., 2002) but yeasts were the predominant microorganisms in brines of Kalamata olives fermented at $7 \% \mathrm{NaCl}$ (Bonatsou et al., 2018) and $8 \% \mathrm{NaCl}$ (Bleve et al., 2015), whereas maintaining $\mathrm{NaCl}$ content below 4\% allowed LAB growth (Tataridou \& Kotzekidou, 2015).

Initial acidification of the brine with lactic and acetic acids is also an emerging practice to control $\mathrm{pH}$ during fermentation thereby to assure safety of the product (Romeo, 2012; Bonatsou et al., 2018). However, some processors all over the world avoid the use of these organic acids because of their objections for the changes that may induce in the organoleptic and physical characteristics of the olives. The lower the $\mathrm{pH}$ in brine, the more purple color of the olives will be reached due to the bathochromic changes of anthocyanins (Romero et al., 2004a). In this study, initial acidification of the brine was not employed at industrial scale to favor black color of olives although it allowed $\mathrm{pH}$ in brine higher than 4.3 units during fermentation. However, it has recently been discovered that maintaining green olives under an overpressure of oxygen for 1-2 days 
leads to a reduction of the olive bitterness and contribute to darkening of the fruit (García et al., 2008; Ramírez et al., 2016). Hence, it was evaluated at pilot plant scale to preserve the black olives with initial acidification of the brine and, subsequently, to submit them to this new technology in order to achieve good black color in the final product.

Preserving black olives without initial acidification of the brines gives rise to $\mathrm{pH}$ higher than recommended 4.3 units during fermentation (IOC, 2004). However, previous works have demonstrated that foodborne pathogenic bacteria could not grow in brines of natural black olives of the Kalamata cultivar at pH below 3.6 (Medina et al., 2013) or olives of the Conservolea cultivar at pH below 4.0 (Grounta et al., 2013). There is only one study that reported the inactivation of these microorganisms in olives with $\mathrm{pH}$ higher than 4 units (Tataridou \& Kotzekidou, 2015), and it has never tested in olives of the Empeltre cultivar fermented under aerobic conditions at industrial level. It must be noticed that some studies have described the presence of foodborne pathogenic bacteria in table olives (Pereira et al., 2008; Romeo, 2012).

Precisely, the phenolic compounds present in natural olives and brines have been attributed as one of the factors responsible for the unfavorable environment that they account for pathogenic bacteria growth (Medina et al., 2013; Tataridou \& Kotzekidou, 2015), and they have been characterized and quantified in this work. Natural olives are very rich in free phenolic compounds such as hydroxytyrosol which is recognized with many bioactive activities (Romero et al., 2004b; Malheiro et al., 2014; Serreli et al., 2017). Additionally, the absence of alkali treatment to debitter these natural olives gives rise to a very high content in them of other bioactive substances as they are the triterpenic acids (Romero et al., 2010, Alexandraki et al., 2014; Durante et al., 2018).

The aim of this work was to generate knowledge for the first time on the industrial processing of natural black olives fermented under aerobic conditions, to know the microbiological stability and to investigate ways to improve the organoleptic characteristics of this food product as well as to contribute to its valorization.

\section{Materials and methods}

Industrial processing of olives 
Olives of the Empeltre cultivar were mechanically harvested between December and January during the seasons 2016/2017 and 2017/2018. Fruits were picked when their surface color was in the black stage of ripeness (3/4 of the flesh was black), which is appropriate for processing as natural black olives. On arrival to the factories located in Alcañiz and Calaceite (Teruel, northeast Spain), leaves and small branches were removed from the fruits that were subsequently washed with tap water and put into tanks. Five tanks containing about $16,000 \mathrm{~kg}$ of fruits and $8,000 \mathrm{~L}$ of brine were monitored each season in the farmer cooperative of Calaceite, and another five tanks containing about $5,000 \mathrm{~kg}$ of olives and $3,000 \mathrm{~L}$ of brine in the farmer cooperative of Alcañiz. Olives were covered with $6 \%(\mathrm{w} / \mathrm{v})$ initial $\mathrm{NaCl}$ brine solution and this salt level was kept constant by adding solid salt at regular time intervals. Aerobic conditions were maintained during fermentation by fitting an aeration column inside the tanks as reported by De Castro et al (2007), and air was bubbled from the bottom of the column at a rate of $0.3 \mathrm{~L}$ of air per hour and $\mathrm{kg}$ of olives, for $8 \mathrm{~h}$ a day, five days a week. The olives were kept in the tanks until their commercialization, which does not happen before 250 days of brining, which is when the fruits have lost their bitterness.

\section{Microbiological analyses of brines}

The viable and culturable populations of lactic acid bacteria (LAB), and yeast and molds were determined by plating the fermentation brines of the industrial tanks and their decimal dilutions (in $9 \mathrm{~g} / \mathrm{L} \mathrm{NaCl}$ ) with a Spiral Plater (Don Whitley Sci. Ltd., Shipley, England). The culture media used were De Man, Rogosa, Sharpe MRS agar (Biokar diagnostics, Beauvais, France) with and without $0.2 \mathrm{~g} / \mathrm{L}$ sodium azide (SigmaAldrich); and glucose (2 g/L)-yeast extract $(0.5 \mathrm{~g} / \mathrm{L})$ agar with and without oxytetracycline (Oxoid Ltd., Basingstoke, England) for the aforementioned groups, respectively. MRS plates were incubated under anaerobic conditions (AnaeroGen, Oxoid). Plates were incubated at $32^{\circ} \mathrm{C}$ for up to five days, and the numbers of colony forming units were counted with a Scan 500 (Interscience, St Nom la Bretèche, France) colony counter. Phase contrast microscopical observations were carried out when colony morphologies were doubtful.

\section{Chemical analyses and olive color}


The concentration of $\mathrm{NaCl}$ was analyzed by titration with a $0.1 \mathrm{~N}$ silver nitrate solution. Free acidity and $\mathrm{pH}$ of brine was measured with a Metrohm 670 Titro processor (Herisau, Switzerland) (De Castro et al., 2007). The surface color of the fruits was expressed as reflectance at $700 \mathrm{~nm}\left(\mathrm{R}_{700}\right)$ using a BYK-Gardner Model 9000 Color view spectrophotometer (Silver Spring, Md., USA).

\section{Phenolic compounds analysis}

Phenolic compounds were extracted from the olive pulp with dimethyl sulfoxide (DMSO) according to García et al (2018). Briefly, small pieces of pulp ( $<0.5 \mathrm{~g})$ were cut from 20 olives up to a total of $10 \mathrm{~g}$ that were introduced into a solution of $30 \mathrm{~mL}$ of DMSO. The mixture was crushed with an Ultra-Turrax homogenizer and, after $30 \mathrm{~min}$ of resting contact, it was centrifuged at $6,000 \mathrm{~g}$ for $5 \mathrm{~min}$, and $0.25 \mathrm{~mL}$ of the supernatant were diluted with $0.5 \mathrm{~mL}$ of DMSO plus $0.25 \mathrm{~mL}$ of $0.2 \mathrm{mM}$ syringic acid (internal standard). The mixture was filtered through a $0.22 \mu \mathrm{m}$ pore size nylon filter, and an aliquot $(20 \mu \mathrm{L})$ was injected into the chromatograph.

The analysis of the phenolic compounds in the brine was carried out by mixing $0.25 \mathrm{~mL}$ of brine, $0.25 \mathrm{~mL}$ of internal standard ( $2 \mathrm{mM}$ of syringic acid), and $0.5 \mathrm{~mL}$ of deionized water. After filtering, the mixture $(20 \mu \mathrm{L})$ was injected into the chromatograph.

\section{Triterpenic acid analysis}

These substances were analyzed following the procedure described by Romero et al (2010) with slight modifications. One gram of dried olive was mixed in a $10 \mathrm{~mL}$ centrifuge tube with $4 \mathrm{~mL}$ of methanol/ethanol (1:1, v/v) and vortexed for $1 \mathrm{~min}$, centrifuged at $6000 \mathrm{~g}$ for $5 \mathrm{~min}$, and the solvent was separated from the solid phase. This step was repeated six times, and the pooled solvent extract was vacuum evaporated. The residue was dissolved in $4 \mathrm{~mL}$ of methanol, which was filtered through $0.22 \mu \mathrm{m}$ pore size nylon filter and an aliquot $(20 \mu \mathrm{L})$ was injected into the chromatograph.

\section{Effect of the temperature on the dialdehydic form of decarboxymethyl elenolic acid linked to hydroxytirosol formation}


Harvested black olives of the Empeltre cultivar were put into $100 \mathrm{~mL}$ jars and covered with $8 \%(\mathrm{w} / \mathrm{v}) \mathrm{NaCl}$ brine. Eighteen jars were incubated at 7, 20 and $28{ }^{\circ} \mathrm{C}$ for 50 days, and duplicate jars were removed after 10, 20 and 50 days for phenolic compounds analysis.

\section{Survival of pathogenic bacteria in olive brines}

Four foodborne pathogenic bacteria were chosen to investigate their survival in brines. Four strains of each species were obtained from the Spanish Type Culture Collection (CECT, Valencia, Spain). Listeria monocytogenes CECT 4031 ${ }^{\mathrm{T}}$, CECT 4032, CECT 5366 and CECT 7467 were cultured at $37^{\circ} \mathrm{C}$ in Brain Heart Infusion (Oxoid Ltd., Basingstoke, Hampshire, England) with or without 1.5\% agar. Sthaphylococcus aureus CECT 86 ${ }^{\mathrm{T}}$, CECT 239, CECT 240 and CECT 976; Salmonella enterica CECT 722 ${ }^{\mathrm{T}}$, CECT 443, CECT 4156 and CECT 4300; Escherichia coli CECT 434 and the strains with serotype O157:H7 CECT 4267, CECT 4782 and CECT 5947 were all cultured at $37{ }^{\circ} \mathrm{C}$ in nutrient broth prepared with $5 \mathrm{~g} / \mathrm{L} \mathrm{Lab}$-Lemco powder (Oxoid), $10 \mathrm{~g} \mathrm{~L}^{-1}$ of neutralized bacteriological peptone (Oxoid), $5 \mathrm{~g} / \mathrm{L} \mathrm{NaCl}$, and $15 \mathrm{~g} / \mathrm{L}$ of agar in the case of solid medium ( $\mathrm{pH}$ 7.2). All the species were maintained at $-80{ }^{\circ} \mathrm{C}$ in the adequate culture broths with $20 \%$ glycerol. Before the experiments, each strain was cultured twice in their respective broths with a previous pre-adaptation phase where $\mathrm{NaCl}(4.5$ $\%$ ) was added in order to acclimatize the microorganisms to the olive brines. Overnight cultures were centrifuged, washed and resuspended in sterilized saline solution $(0.9 \%$ $\mathrm{NaCl}$ ). Cocktails of each species were obtained mixing equal quantities of the corresponding strains. The volumes were calculated to obtain $5.9-6.2 \log \mathrm{CFU} / \mathrm{mL}$ as initial inoculum when $50 \mu \mathrm{L}$ of the suspension was added to $1.5 \mathrm{~mL}$ of the different tested brines.

Control test solution ( $5 \% \mathrm{NaCl}$ buffered at $\mathrm{pH} 5.5)$ and industrial brines were filtersterilized $(0.22 \mu \mathrm{m}$ pore size). Three different brines from olives fermented in industrial tanks for one year (old brines) and other three brines from olives fermented for only 40 days (fresh brines) were used for the experiments. The challenge tests were performed in duplicate at room temperature $\left(20 \pm 2{ }^{\circ} \mathrm{C}\right)$ and refrigerated $\left(4 \pm 1{ }^{\circ} \mathrm{C}\right)$. Before inoculation, brines were previously acclimatized to corresponding temperature. Samples from each tube were removed at different times, diluted in $0.1 \%$ sterile peptone water and plated on the appropriate solid media for each species to count cultivable cells (Medina et al., 2013). 


\section{Assay to improve the black color of olives}

One kilogram of five samples of olives fermented for 40 days during the 2016/2017 season were put into a modified Oxoid anaerobic jar of $3.5 \mathrm{~L}$ of capacity (Oxoid, Ltd., Basingstoke, U.K.) with a pressure gauge. Oxygen was introduced through the inlet valve and expulsed through the outlet valve for $5 \mathrm{~min}$. The outlet valve was closed, and an overpressure was maintained in the jar for $48 \mathrm{~h}$ under ambient temperature. Seven hundred grams of oxidized olives were put into 1.3 L PVC vessel and covered with the same fermentation brine but spiked with $0.6 \%$ acetic acid. Olives not submitted to that oxidation treatment were also covered with the same acidified brine (control). All samples in duplicate were preserved under anaerobic conditions for 160 days at the Instituto de la Grasa pilot plant (Seville, Spain) at ambient temperature.

\section{Statistical analysis}

Data comparisons were subjected to one-way factor analysis of variance (ANOVA). Significant differences were separated using Duncan test. The level of significance was set at $\mathrm{p}<0.05$. All statistical analyses were carried out using the STATISTICA 8.0 software (StatSoft software package, Tulsa, OK, USA).

\section{Results and discussion}

\section{Fermentation}

The prevailing microbial population in the fermentation brines of Empeltre black olives after 7-9 months of brining is presented in Table 1. Yeasts were detected in all brines despite the olive season and location, whereas LAB were only found in some tanks, particularly in those located in Alcañiz and during the 2017/2018 season. The only exception in Calaceite was one tank during the 2017/2018 season in which LAB grew from the onset of the brining. It must be noted that the Alcañiz olives were mainly harvested from irrigated trees, which is favorable for the growth of LAB in brines of natural olives (Martorana et al., 2017).

The level of salt is a limiting factor for the growth of LAB. Tassou et al $(2002,2007)$ found that $\mathrm{LAB}$ grew in brines of natural Greek black olives with $\mathrm{NaCl}$ content below 6 $\%(\mathrm{w} / \mathrm{v})$ but a level of $8 \%(\mathrm{w} / \mathrm{v})$ inhibited their growth. However, it has also been 
reported the growth of these microorganisms in brines of Italian natural olives with $8 \%$ $\mathrm{NaCl}$ (Randazzo et al., 2017). In our industrial assays under aerobic conditions the initial level of $\mathrm{NaCl}$ was $6 \%$, which was maintained with periodical addition of coarse salt, although it was not high enough to prevent lactic acid fermentation in some tanks.

There have been many studies to enhance LAB growth in brines of natural black and green olives with the aim of forming lactic acid in order to drop the $\mathrm{pH}$ below 4.3, and consequently to fulfil the international standard for natural olives (Tataridou \& Kotzekidou, 2015; Randazzo et al., 2017). However, this lactic acid fermentation also leads to a characteristic flavor and color of the product that it is not desirable in many producing countries such as Spain.

Precisely, the $\mathrm{pH}$ decreased rapidly during the first two months of brining and the free acidity increased to a large extent in the tanks where LAB grew. Indeed, the $\mathrm{pH}$ reached a value below 4.0 units after 250 days of brining. In contrast, the $\mathrm{pH}$ was maintained above 4.3 units in the brines where yeasts were the predominant microorganisms and LAB did not grow. These differences are clearly noticed when comparing the evolution of $\mathrm{pH}$ and acidity between the only tank where LAB grew and the rest of Calaceite season 2017/2018 tanks (Figure 1). Therefore, the industrial aerobic conditions did not prevent the growth of LAB in brines of the Empeltre natural olives and the level of salt should be increased above $6 \%$ in case of LAB growth inhibition is wanted.

\section{Changes in phenolic composition during fermentation}

In the case of Empeltre olives there was no knowledge on the composition of phenolic substances until now. The major phenolic compound in raw fruit was demethyloleuropein $(7380 \pm 1865 \mathrm{mg} / \mathrm{kg})$, followed by oleuropein $(2423 \pm 770 \mathrm{mg} / \mathrm{kg})$, hydroxytyrosol-4-glucoside $(1504 \pm 416 \mathrm{mg} / \mathrm{kg})$, verbascoside $(476 \pm 165 \mathrm{mg} / \mathrm{kg})$ and others $(371 \pm 231 \mathrm{mg} / \mathrm{kg})$, which is a similar pattern that found for raw Arbequina olives (Romero et al., 2017). To our knowledge, Empeltre and Arbequina are the only two olive cultivars that contain a higher concentration of demethyloleuropein than oleuropein in the pulp of the raw fruit. It must also be noticed that the content of hydroxytyrosol-4-glucoside was lower than that of the secoiridoid glucosides despite the concentration of the former substance increases with olive maturation. 
Surprisingly, neither demethyloleuropein nor oleuropein were detected in both brine and pulp of the Empeltre olives after only 15-20 days of brining, whereas oleuropein is present for a long time in the fermentation brines of Hojiblanca and Manzanilla natural olives (Romero et al., 2004a; Ramírez et al., 2017a).

In contrast, HyEDA was detected in a very high concentration in the pulp of the Empeltre olives from the onset of the fermentation (Figure 2) although its content in the olives and brine decreased throughout the fermentation process. It seems that the enzymatic hydrolysis of demethyloleuropein by the action of ß-glucosidase was very rapid during the first 1-2 weeks, thereafter a slow chemical hydrolysis of the HyEDA occurred (Medina et al., 2008). This hypothesis was confirmed by the continuous increase of hydroxytyrosol in both brine and pulp as a consequence of HyEDA hydrolysis (Figure 3). It must be noticed that the concentration of HyEDA was always higher in the pulp than in the brine and the opposite for hydroxytyrosol.

An explanation for the rapid and complete enzymatic hydrolysis of demethyloleuropein and oleuropein in olives of the Empeltre cultivar may be the low temperature during the first months of brining. These olives are harvested fully ripened during December and January at Teruel (Spain) where the climate is very cold in winter, and it has been reported that inactivation of $\beta$-glucosidase during olive brining increases with increase ambient temperature (Ramírez et al., 2017a). To confirm it, olives of the Empeltre cultivar were brined at 7,20 and $28^{\circ} \mathrm{C}$ during 50 days at laboratory scale and results are presented in Figure 3. The highest formation of HyEDA was reached at $7{ }^{\circ} \mathrm{C}$, which is in agreement with previous results reported for Manzanilla and Hojiblanca cultivars (Ramírez et al., 2017a).

\section{Content in bioactive substances}

Table 2 shows the data of phenolic compounds and triterpenic acids found in fermented olives of the two seasons analyzed and data of two samples of commercial packed olives. As expected, the major phenolic compound in both fermented and packed olives was hydroxytyrosol, followed by verbascoside and other substances in minor content. It can be observed a great difference between seasons and commercial product, ranging the total phenolic concentration from $1,003 \mathrm{mg} / \mathrm{kg}$ to $2,020 \mathrm{mg} / \mathrm{kg}$, which is a much higher content than reported for California-style black olives and Spanish-style green 
olives (Romero et al., 2004b; García et al., 2018) or even for Italian and Greek natural black olives (Durante et al., 2018).

With respect to triterpenic acids, the total concentration of these substances ranged from $2,343 \mathrm{mg} / \mathrm{kg}$ to $2,682 \mathrm{mg} / \mathrm{kg}$, which is a similar content than found for Italian and Greek natural black olives and much higher than reported for California-style black olives and Spanish-style green olives (Romero et al., 2010; Durante et al., 2018). All these data confirmed the high content in bioactive substances of natural black olives, particularly those of the Empeltre cultivar.

\section{Survival of foodborne pathogenic bacteria}

The olives once fermented and debittered can be consumed in bulk or packaged in small containers, and safety and absence of pathogenic microorganisms have to be guaranteed. It must be said that the $\mathrm{pH}$ of these brines ranged from 4.3 to 4.5 units, which was higher than tested in previous assays with Greek olive brines (Medina et al., 2013; Grounta et al., 2013). Besides, the maximum pH limit for natural olives is 4.3 (IOC, 2004), although this international standard also states that trade preparations of table olives not complying with this characteristic may be marketed if they are made according to traditional methods, the food safety of which is guaranteed by an official body which authorizes their distribution and sale, which is the case for these Empeltre olives. Survival experiments of foodborne pathogenic bacteria in old (one year) and new (40 days) brines of Empeltre olives were carried out with the aim of characterizing their bactericidal effect. The results confirmed that the brine of natural olives is a harsh environment for these microorganisms, even at $\mathrm{pH}$ above 4.3 units. Irrespective of the storage temperature (room or refrigeration), the populations of $S$. enterica, $S$. aureus, $E$. coli and L. monocytogenes were reduced in more than 5 logs by $1 \mathrm{~h}$ from their inoculation into most of the olive brines (Table 3). However, L. monocytogenes and $S$. aureus were the most resistant species, which is in agreement with previously data reported in olive brines of Conservolea, Manzanilla, Gordal, Hojiblanca and Aloreña cultivars (Grounta et al., 2013; Medina et al., 2013, 2018). In particular, L. monocytogenes survived in a new olive brine more than $24 \mathrm{~h}$ under refrigeration conditions (Table 3). The own phenols of the olives or their derivatives in brine constitute one of the factors that influence the bacterial survival in olive brines, especially the dialdehydic form of decarboxymethyl elenolic acid linked to 
hydroxytyrosol (HyEDA), has a strong effect against LAB and other bacteria (Medina et al., 2010; 2013).

\section{Assay to improve the black color of olives}

Unfortunately, HyEDA is a bitter compound similarly to oleuropein so that many months are necessary to market the Empeltre olives before this substance is chemically hydrolyzed (Figure 4). Besides, the initial black color of the raw olives changes to dark brown, brown or even pink color, depending of the degree of ripeness of the fruit, during the fermentation stage (Romero et al., 2004a).

Hence, it is a current practice in many countries to expose the fermented olives to open air before packing with the aim of darkening the fruit. In fact, the use of aerobic conditions during fermentation could contribute to the darkening of the olives but it is not as effective as putting directly the fruit to open air (Juárez-Romero et al., 2015). Microorganisms in the brines of the olives consume the oxygen introduced in the tanks working under aerobic conditions and the gas is not available for the oxidation of the phenolic compounds.

Recently, it has been developed a method to debitter and darken natural green olives in only a few days by putting the fruit under an overpressure of oxygen (García et al., 2008; Ramírez et al., 2016). The results of the experiments carried out with Empeltre olives fermented for 40 days in industrial tanks are depicted in Figure 4. Fruit lowered their reflectance at $700 \mathrm{~nm}$ from 16.02 to 12.06 units thereby darker olives were achieved after the oxidation process. It is interesting to highlight that brown olives changed to black olives so that the black color of the whole olive lot was more homogeneous. After the oxidation step, olives were preserved for 160 days in the original brine that was also acidified with acetic acid. Obviously, the reflectance increased from 12.06 to 15.4 units but it also increased from 16.02 to 19.18 in olives none submitted to oxidation and preserved in the acidified brine. Although none statistically significant, the color of the olives submitted to oxidation and preserved in the acidified brine for 160 days $\left(\mathrm{R}_{700}=15.4\right)$ was darker than that of the olives obtained directly from the industrial tanks $\left(\mathrm{R}_{700}=16.02\right)$. Therefore, this methodology is recommended for natural black olives to reach the valued black color of this commercial product. 


\section{Conclusion}

The studies at industrial scale of the aerobic fermentation of natural black olives of the Empeltre cultivar revealed that yeasts were the prevalent microorganisms in all cases, whereas the presence of lactic acid bacteria was irregular. It was demonstrated that the brines of these olives constitute a harsh environment for some foodborne pathogenic bacteria, which can probably be attributed, among other variables, to the presence of phenolic compounds with high antibacterial activity. In particular, it has been observed a very high concentration of HyEDA in the pulp of the olives from the beginning of the fermentation, that it was slowly hydrolyzed with the subsequent increase of the hydroxytyrosol concentration. These fermented olives of the Empeltre cultivar can be considered as very rich in phenolic compounds as well as triterpenic acids, which are bioactive substances with many attributed beneficial properties for human health.

\section{Acknowledgments}

We are grateful to Alejandra Expósito for her technical assistance. This study was partly supported by Cooperativa de Aceites del Matarraña SCL, Calaceite (Teruel, Spain) and Cooperativa Nuestra Señora de los Pueyos, Alcañiz (Teruel, Spain).

\section{Conflict of interest}

The authors declare no conflict of interest.

\section{References}

Alexandraki, V., Gerogalaki, M., Papadimitriou, K., Anastasiou, R., Zoumpopoulou, G., Chatzipavlidis, I., Papadelli, M., Vallis, N., Moschochoritis, K. \& Tsakalidou, E. (2014). Determination of triterpenic acids in natural and alkaline-treated Greek table olives throughout the fermentation process. LWT-Food Science and Technology, 58, 609-613.

Bleve, G., Tufariello, M., Durante, M., Grieco, F, Ramires, F. A., Mita, G., TasioulaMargari, M. \& Logrieco, A. F. (2015). Physico-Chemical characterization of 
natural fermentation process of Conservolea and Kalamata table olives and development of a protocol for the pre-selection of fermentation starters. Food Microbiology, 46, 368-382.

Bonatsou, S., Paramithiotis, S. \& Panagou, E. Z. (2018). Evolution of yeast consortia during the fermentation of Kalamata natural black olives upon two initial acidification treatments. Frontiers in Microbiology, 8, 2673.

De Castro, A., García, P., Romero, C., Brenes, M. \& Garrido, A. (2007). Industrial implementation of black ripe olive storage under acidic conditions. Journal of Food Engineering, 80, 1206-1212.

Durante, M., Tufariello, M., Tommasi, L., Lenucci, M. S., Bleve, G. \& Mita, G. (2018). Evaluation of bioactive compounds in black table olives fermented with selected microbial starters. Journal of the Science of the Food and Agriculture, 98, 96-103.

García, P., Durán, M. C. \& Garrido, A. (1985). Aerobic fermentation of natural black olives in brine. Grasas y Aceites, 36, 14-20.

García, A., Romero, C., Medina, E., García, P., de Castro, A. \& Brenes, M. (2008) Debittering of olives by polyphenol oxidation. Journal of Agricultural and Food Chemistry, 56, 11862-11867.

García, P., Romero, C. \& Brenes, M. (2018). Bioactive substances in black ripe olives produced in Spain and the USA. Journal of Food Composition and Analysis, 66, 193-198.

Grounta, A., Nychas, G. J. N. \& Panagou, E. Z. (2013). Survival of food-borne pathogens on natural black table olives after post-processing contamination. International Journal of Food Microbiology, 161, 197-202.

IOC, International Olive Council. (2004). Unified qualitative standard applicable for table olives in international trade. Madrid. Spain. http://www.internationaloliveoil.org.

Juarez-Romero, J. A., Denoya, G. \& Polenta. (2015). Influence of alternating air injection on the color and "alambrado" of natural black olives cv. Arauco, as compared with the traditional Argentine method. Grasas Aceites, 66, e070. 
Malheiro, R., Mendes, P., Fernandes, F., Rodrigues, N., Bento, A. \& Pereira, J. A. (2014). Bioactivity and phenolic composition from natural fermented table olives. Food \& Function, 5, 3132-3142.

Martorana, A., Miceli, C., Alfonzo, A., Settani, L., Gaglio, R., Caruso, T., Moschetti, G. \& Francesca, N. 2017. Effects of irrigation treatments on the quality of table olives produced with the Greek-style process. Annals of Microbiology, 67, 37-48.

Medina, E., Romero, C., Brenes, M., García, P., de Castro, A. \& García, A. (2008). Profile of anti-lactic acid bacteria compounds during the storage of olives which are not treated with alkali. European Food Research and Technology, 228, 133138.

Medina, E., Gori, C., Servili, M., de Castro, A., Romero, C. \& Brenes, M. (2010). Main variables affecting the lactic acid fermentation of table olives. International Journal of Food Science and Technology, 45, 1291-1296.

Medina, E., Brenes, M., Romero, C., Ramírez, E. \& de Castro, A. (2013). Survival of foodborne pathogenic bacteria in table olive brines. Food Control, 34, 719-724.

Pereira, A. P., Pereira, J. A., Bento, A. \& Estevinho, M. L. (2008). Microbiological characterization of table olives commercialized in Portugal in respect to safety aspects. Food and Chemical Toxicology, 46, 2895-2902.

Ramírez, E., García, P., Brenes, M. \& Romero, C. (2016). Evaluation of chemical components of debittered olives undergone preservation and polyphenol oxidation. International Journal of Food Science and Technology, 51, 1674-1679.

Ramírez, E., Medina, E., García, P., Brenes, M. \& Romero, C. (2017). Optimization of the natural debittering of table olives. LWT-Food Science and Technology, 77, 308-313.

Randazzo, C. L., Todaro, A., Pino, A., Pitino, I., Corona, O. \& Caggia, C. (2017). Microbiota and metabolome during controlled and spontaneous fermentation of Necellara Etnea table olives. Food Microbiology, 65, 136-148. 
Romeo, F. V. (2012). Microbiological aspects of table olives. In: Olive Germplasm The Olive Cultivation, Table Olive and Olive Oil Industry in Italy (edited by I. Muzzalupo). Pp. 321-342. InTech, Italy. http://dx.doi.org/10.5772/51479.

Romero, C., Brenes, M., García, P., García, A., Garrido, A. (2004a). Polyphenol changes during fermentation of naturally black olives. Journal of Agricultural and Food Chemistry, 52, 1973-1979.

Romero, C., Brenes, M., Yousfi, K, García, P., García, A. \& Garrido, A. (2004b). Effect of cultivar and processing method on the contents of polyphenols in table olives. Journal of Agricultural and Food Chemistry, 52, 479-484.

Romero, C., García, A., Medina, E., Ruíz-Méndez, Mª V., de Castro, A. \& Brenes, M. (2010). Triterpenic acids in table olives. Food Chemistry, 118, 670-674.

Romero, C., Medina, E., Mateo, Ma A. \& Brenes, M. (2017). Quantification of bioactive compounds in Picual and Arbequina olive leaves and fruits. Journal of the Science of the Food and Agriculture, 97, 1725-1732.

Romero-Gil, V., Medina, E., Garrido, A. \& Arroyo, F. N. (2018). Foodborne pathogen survival in comercial Aloreña de Málaga table olive packaging. Frontiers in Microbiology, 9, 2471.

Serreli, G., Incani, A., Atzeri, A., Angioni, A., Campus, M., Cauli, E., Zurru, R. \& Deiana, M. (2017). Antioxidant effect of natural table olives phenolic extracts against oxidative stress and membrane damage in enterocyte-like cells. Journal of Food Science, 82, 380-385.

Tassou, C. C., Panagou, E. Z. \& Katsaboxakis, K. Z. (2002). Microbiological and physicochemical changes of naturally black olives fermented at different temperatures and $\mathrm{NaCl}$ levels in the brines. Food Microbiology, 19, 605-615.

Tassou, C. C., Katsaboxakis, K. Z., Georget, D. M. R., Parker, M. L., Waldron, K. W., Smith, A. C. \& Panagou, E. Z. (2007). Effect of calcium chloride on mechanical properties and microbiological characteristics of cv. Conservolea naturally black olives fermented at different sodium chloride levels. Journal of the Science of Food and Agriculture, 87, 1123-1131. 
Tataridou, M. \& Kotzekidou, P. (2015). Fermentation of table olives by oleuropeinolytic starter culture in reduced salt brines and inactivation of Escherichia coli O157:H7 and Listeria monocytogenes. International Journal of Food Microbiology, 208, 122-130. 


\section{Figure legends}

Figure 1 Evolution of the $\mathrm{pH}$ and free acidity in brines of Empeltre olives fermented under aerobic conditions at Calaceite during the 2017/2018 season. Values of yeast fermentation are the mean of Table $1 \mathrm{~B}-\mathrm{E}$ tanks and lactic acid fermentation correspond to tank A. Symbols: $\downarrow \mathrm{pH}$ (yeast fermented); $\boldsymbol{\Delta}$ acidity (yeast fermented); $\boldsymbol{\nabla} \mathrm{pH}$ (LAB fermented); $\bullet$ acidity (LAB fermented). Standard deviation of 4 values is depicted for yeast fermentation tanks.

Figure 2 Evolution of HyEDA (decarboxymethyl elenolic acid linked to hydroxytyrosol) and hydroxytyrosol in pulp and brine of black olives of the Empeltre cultivar during their fermentation step under aerobic conditions. Olives were of the 2016/2017 season and processed at Calaceite. Standard deviation of five values is depicted for each point.

Figure 3 Influence of temperature on the formation during brining of HyEDA in the pulp of black olives of the Empeltre cultivar. Error bars mean standard deviation of duplicates.

Figure 4 Color $\left(\mathrm{R}_{700}\right)$ of black olives fermented for 40 days and kept without treatment (Control) or submitted to oxidation for 2 days (Oxidized) before being preserved for 160 days in acidified brine. Bars mean the standard deviation of 5 samples. Different letters mean significant differences according to a Duncan's multiple range test $(p<0.05)$. 
Table 1 Microbial population ( $\log \mathrm{CFU} / \mathrm{mL}$ ) in the fermenting brines of five tanks per season and location.

\begin{tabular}{|c|c|c|c|c|c|}
\hline \multirow[b]{3}{*}{ Tanks } & & \multicolumn{4}{|c|}{ Location } \\
\hline & & \multicolumn{2}{|c|}{ Alcañiz } & \multicolumn{2}{|c|}{ Calaceite } \\
\hline & & Yeasts & LAB & Yeasts & LAB \\
\hline \multicolumn{6}{|c|}{$\begin{array}{l}\text { Season } 2016 / 2017 \\
\left.\text { (month } 7^{\text {th }}\right)\end{array}$} \\
\hline & $\mathrm{A}$ & $6.0(0.1)$ & ND & $6.1(0.0)$ & ND \\
\hline & B & $5.8(0.0)$ & ND & $5.9(0.0)$ & ND \\
\hline & $\mathrm{C}$ & $5.8(0.1)$ & ND & $6.2(0.1)$ & ND \\
\hline & D & $5.9(0.1)$ & ND & $6.1(0.0)$ & ND \\
\hline & $\mathrm{E}$ & $5.4(0.0)$ & $6.3(0.3)$ & $6.1(0.1)$ & ND \\
\hline \multicolumn{6}{|c|}{$\begin{array}{l}\text { Season } 2017 / 2018 \\
\text { (month } 9^{\text {th }} \text { ) }\end{array}$} \\
\hline & $\mathrm{A}$ & $5.1(0.3)$ & $6.5(0.0)$ & $4.8(0.1)$ & $6.0(0.1)$ \\
\hline & B & $5.2(0.1)$ & $6.8(0.2)$ & $5.8(0.0)$ & ND \\
\hline & $\mathrm{C}$ & $6.2(0.0)$ & ND & $6.0(0.0)$ & ND \\
\hline & $\mathrm{D}$ & $4.4(0.2)$ & $6.7(0.5)$ & $5.8(0.0)$ & ND \\
\hline & $\mathrm{E}$ & & & $5.9(0.1)$ & ND \\
\hline
\end{tabular}


Table 2 Bioactive compounds $(\mathrm{mg} / \mathrm{kg}$ ) in fermented and commercial natural black olives of the Empeltre cultivar

\begin{tabular}{|c|c|c|c|c|}
\hline & $\begin{array}{l}\text { Olives (season } \\
2016 / 2017 \text { ) }\end{array}$ & $\begin{array}{l}\text { Olives (season } \\
2017 / 2018 \text { ) }\end{array}$ & $\begin{array}{l}\text { Commercial } \\
\text { olives A }\end{array}$ & $\begin{array}{l}\text { Commercial } \\
\text { olives B }\end{array}$ \\
\hline \multicolumn{5}{|l|}{ Phenolic compounds } \\
\hline Hydroxytyrosol & 1501 (133)a & $939(160) b$ & $975(97) b$ & $739(11) b$ \\
\hline Verbascoside & 203 (106)a & $192(55) \mathrm{a}$ & $198(10) \mathrm{a}$ & $106(12) a$ \\
\hline Tyrosol & $124(8) \mathrm{a}$ & $67(12) \mathrm{b}$ & $87(10) b$ & $45(7) b$ \\
\hline Rutin & $56(14) a$ & $30(2) b$ & $29(5) b$ & $20(2) b$ \\
\hline Luteolin & $96(11) a$ & 49 (11)a & $55(12) \mathrm{a}$ & $48(7) a$ \\
\hline Others* & $40(28) a$ & 67 (18)a & $52(13) \mathrm{a}$ & $45(5) a$ \\
\hline Total & $2020(162) a$ & $1344(230) b$ & $1396(119) b$ & $1003(20) b$ \\
\hline \multicolumn{5}{|l|}{ Triperpenic acids } \\
\hline Maslinic acid & $1573(553) \mathrm{a}$ & 1687 (227)a & $1841(92) \mathrm{a}$ & $1852(447) \mathrm{a}$ \\
\hline Oleanolic acid & $770(260) \mathrm{a}$ & $762(57) \mathrm{a}$ & 898 (13)a & $830(159) \mathrm{a}$ \\
\hline Total & $2343(805) \mathrm{a}$ & $2450(283) \mathrm{a}$ & $2739(78) \mathrm{a}$ & $2682(606) \mathrm{a}$ \\
\hline
\end{tabular}


Table 3 Bactericidal effect of olive brines against different bacterial cocktails inoculated and kept at room temperature $\left(20 \pm 2^{\circ} \mathrm{C}\right)$ or refrigerated $\left(4 \pm 1^{\circ} \mathrm{C}\right)$.

\begin{tabular}{|c|c|c|c|c|c|c|c|c|c|c|}
\hline & & \multicolumn{2}{|c|}{$\begin{array}{c}\text { S. enterica } \\
(\log \mathrm{CFU} / \mathrm{mL})\end{array}$} & \multicolumn{3}{|c|}{$\begin{array}{c}\text { S. aureus } \\
\text { (Log CFU/mL) }\end{array}$} & \multicolumn{2}{|c|}{$\begin{array}{c}\text { E. coli } \\
\text { (Log CFU/mL) }\end{array}$} & \multicolumn{2}{|c|}{$\begin{array}{l}\text { L. monocytogenes } \\
\text { (Log CFU/mL) }\end{array}$} \\
\hline & & $1 \mathrm{~h}$ & $24 \mathrm{~h}$ & $1 \mathrm{~h}$ & $24 \mathrm{~h}$ & $48 \mathrm{~h}$ & $1 \mathrm{~h}$ & $24 \mathrm{~h}$ & $1 \mathrm{~h}$ & $24 \mathrm{~h}$ \\
\hline \multicolumn{11}{|l|}{$\begin{array}{l}\text { Room } \\
\text { temperature }\end{array}$} \\
\hline & Control & $6.2(0.0)$ & $5.8(0.1)$ & $5.9(0.0)$ & $5.4(0.0)$ & - & $6.2(0.1)$ & - & $5.6(0.1)$ & $3.3(0.0)$ \\
\hline & Old brine & $2.0(0.9)$ & $<1.3$ & $1.8(0.7)$ & $<1.3$ & - & $<1.3$ & - & $<1.3$ & - \\
\hline & New brine & $5.3(0.0)$ & $<1.3$ & $3.4(0.0)$ & $<1.3$ & - & $2.2(0.4)$ & $<1.3$ & $5.5(0.0)$ & $<1.3$ \\
\hline & New brine & $<1.3$ & $<1.3$ & $<1.3$ & $<1.3$ & - & $<1.3$ & - & $<1.3$ & - \\
\hline & New brine & $<1.3$ & $<1.3$ & $<1.3$ & $<1.3$ & - & $<1.3$ & - & $<1.3$ & - \\
\hline \multicolumn{11}{|l|}{ Refrigerated } \\
\hline & Control & $6.3(0.1)$ & $5.9(0.1)$ & $5.9(0.0)$ & $5.8(0.1)$ & $5.5(0.6)$ & $6.2(0.1)$ & $6.0(0.1)$ & $6.0(0.1)$ & $5.6(0.1)$ \\
\hline & Old brine & $<1.3$ & $<1.3$ & $<1.3$ & $<1.3$ & - & $<1.3$ & - & $<1.3$ & - \\
\hline & New brine & $<1.3$ & $<1.3$ & $<1.3$ & $<1.3$ & - & $1.9(0.9)$ & - & $2.5(0.4)$ & $<1.3$ \\
\hline & New brine & $<1.3$ & $<1.3$ & $<1.3$ & $<1.3$ & - & $<1.3$ & - & $<1.3$ & - \\
\hline
\end{tabular}

The initial inoculum ranged from 5.9 to $6.2 \log$ CFU/mL. The detection limit was $1.3 \log \mathrm{CFU} / \mathrm{mL}$. Standard deviation of duplicates in parentheses 


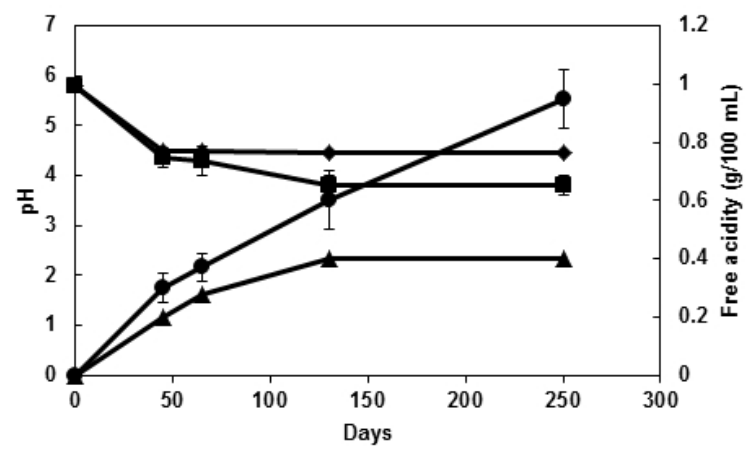

Figure 1

$190 \times 254 \mathrm{~mm}(96 \times 96 \mathrm{DPI})$ 
Figure 2

$190 \times 254 \mathrm{~mm}(96 \times 96$ DPI) 


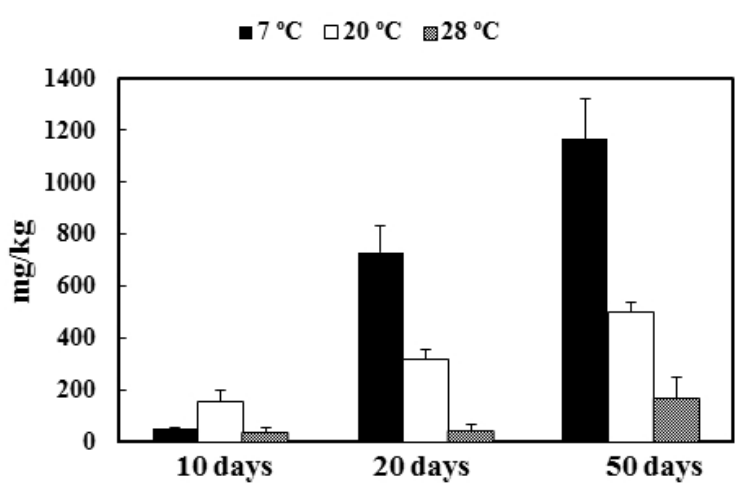

Figure 3

$190 \times 254 \mathrm{~mm}(96 \times 96 \mathrm{DPI})$

Institute of Food Science and Technology 


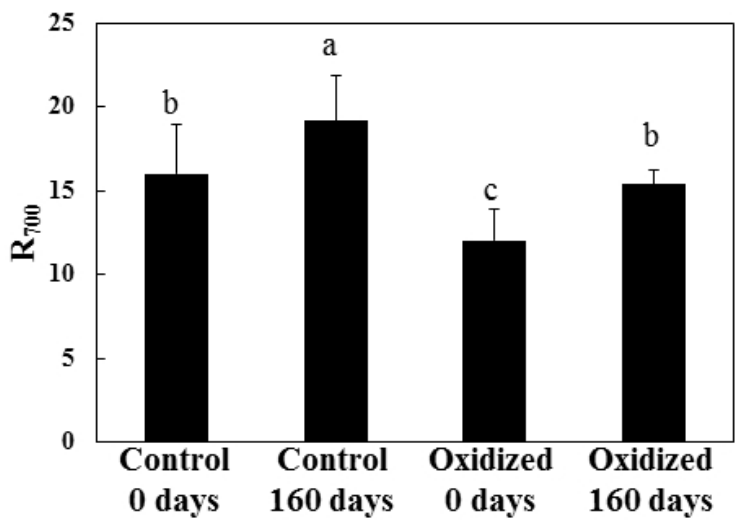

Figure 4

$190 \times 254 \mathrm{~mm}(96 \times 96$ DPI $)$ 
Industrial aerobic fermentation of natural black olives

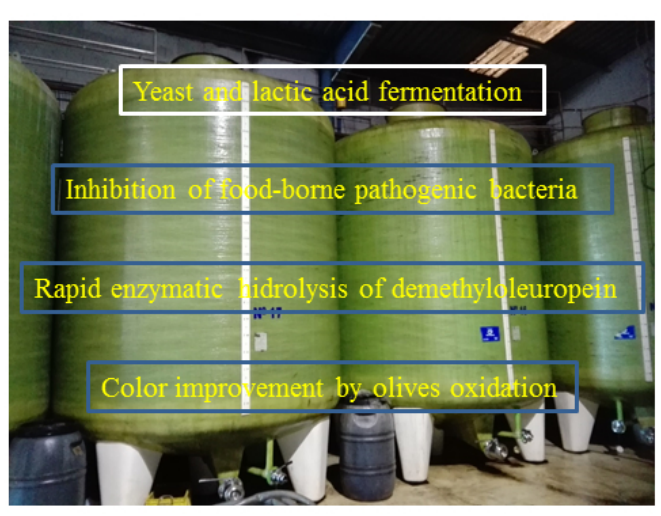

Graphical abstract

$254 \times 190 \mathrm{~mm}(96 \times 96 \mathrm{DPI})$ 